\title{
Immediate Skin Contact Reactions Induced by Chemicals
}

\author{
ELENA GIMÉNEZ-ARNAU
}

Dermatochemistry Laboratory

Institut de Chimie de Strasbourg (CNRS UMR 7177)

Université de Strasbourg

4, Rue Blaise Pascal

67081 Strasbourg

France

Tel: +33 368851525

Fax: +33 368851527

E-mail: egimenez@unistra.fr

\begin{abstract}
:
An ever-expanding list of causes has been reported for immediate skin contact reactions, of which mostly proteins (molecular weight $10000 \mathrm{Da}$ to several hundred thousands), but also chemical compounds of low molecular weight (lower than $1000 \mathrm{Da}$ ). Low molecular weight chemical agents can be indeed responsible for immediate contact skin symptoms in the different defined categories of contact urticaria. The most important chemicals responsible for non-immunological and immunological contact urticaria are described in this chapter. For simplification and comprehension purposes they have been classified into the major containing families of products that include fragrances and cosmetic ingredients, biocides and preservatives and drugs, together with other categories.
\end{abstract}

Key words: Immediate skin reactions, contact urticaria, non-immunological, immunological, occupational, low molecular weight compounds, fragrances, cosmetics, preservatives, drugs, chemicals. 


\section{Introduction}

\section{Non-Immunological and Immunological Contact Urticaria-Triggering Chemicals}

Immediate skin contact reactions are characterized by the instantaneous skin development of itchy flares, wheals and/or dermatitis, following external contact with a substance. They usually manifest as Contact Urticaria (CoU), Contact Urticaria Syndrome (CUS) or Protein Contact Dermatitis (PCD).[1] CoU generally appears within approximately 30 minutes, and clears completely within hours without residual signs of irritation. An ever-expanding list of causes has been reported, of which mostly proteins (molecular weight $10000 \mathrm{Da}$ to several hundred thousands), but also chemical compounds of low molecular weight (LMW) (< $1000 \mathrm{Da})$.

LMW chemical agents can be responsible for immediate contact skin symptoms in the different defined categories of $\mathrm{CoU}$. According to the underlying mechanisms involved, $\mathrm{CoU}$ is classified as non-immunological or immunological. A third category exists for reactions with mixed features or undetermined pathomechanisms.[2] This third category is much less common and will not be treated herein.

Non-immunological $\mathrm{CoU}(\mathrm{NICoU})$ is the most common form of the disease. NICoU occurs without prior exposure to an eliciting substance and without previous sensitization. Chemicals inducing $\mathrm{NICoU}$ are frequently encountered in our environment as biocides or preservatives, fragrances and flavorings in cosmetic products, toiletries, drugs, topical medicaments and foodstuffs.[3,4] Though, there are also other miscellaneous chemicals and metals responsible for these reactions. Most individuals react to these substances with local erythema and/or edema within $45 \mathrm{~min}$ after application, albeit with widely varying intensities of skin reaction.[5] The pathogenesis is not clearly understood. It appears to involve the release of vasogenic mediators without involvement of immunological processes (Fig. 1a). Due to the lack of response to antihistamines and positive responses to acetylsalicylic acid and non-steroidal anti-inflammatory drugs, it has been proposed that the physiopathology involves prostaglandin release from the epidermis rather than histamine release from mast cells.[6,7]

Conversely, immunologic $\mathrm{CoU}$ (ICoU) is an immediate type I hypersensitivity reaction, mediated by allergen-specific immunoglobulin E (IgE) in previously sensitized individuals.[2] Thus, ICoU needs sensitization, and will appear after repeated contacts with the trigger substance. It is more frequent in people with previous atopic symptoms. Histamine release is the major mechanism of action seen. This mechanism includes allergen penetration through the epidermis and binding to IgE at the surface of mast cells and basophiles, causing degranulation and release of histamine and other vasoactive substances such as prostaglandins, leukotrienes and kinins (Fig. 1b).[8] In rare cases, IgG or IgM have been also incriminated. The consequences are potentially more serious than for NICoU, as reactions may not remain localized to the area of contact, and generalized urticaria, or even involvement of organs such as the respiratory and gastrointestinal tract may follow, and end with anaphylactic shock. 
A large number of causes have been documented as producing ICoU. The commonest agents inducing ICoU are food proteins (animal or vegetal), animal proteins and natural rubber latex. These have been largely reviewed.[9,10] However, LMW chemicals including drugs, biocides and preservatives, metals or industrial compounds can also produce ICoU. They are very often present in drugs, cosmetics [11] and industrial preparations. There are extensive lists of proteins and chemicals reported as causing ICoU, only a part of them being reported as occupational.[2,10,12] Most publications about $\mathrm{CoU}$ concern case reports or little series and epidemiological studies are scarce. However, some data indicate that ICoU is not rare, although frequently underestimated. The ultimate evidence corroborating that a compound is responsible for ICoU is the measurement of specific $\operatorname{IgE}$ in the serum of the patient by the radioallergosorbent RAST test whenever possible. The patient's serum is incubated with the agent bound to a solid phase, and the amount of specific IgE recognising and binding to the agent is quantified with radiolabelled anti-IgE.[13] Determination of specific IgE by RAST will confirm type I hypersensitivity, but their ordinary detection is restricted to some compounds, particularly when they are non-proteinaceous.

Table 1 resume the most reported LMW chemical agents producing immediate non-immunologic and immunologic skin reactions.[1,12]. In this chapter, the most important LMW chemicals responsible for $\mathrm{NICoU}$ and $\mathrm{ICoU}$ are described, and classified into the major containing families of products, fragrances and cosmetic ingredients, biocides and preservatives and drugs, together with other categories.

\section{Fragrances and Cosmetics Ingredients}

NICoU reactions to fragrances and to cosmetics ingredients are well known.[14] They have been often reported to some of the constituents of the Fragrance Mix I (FMI) and to balsam of Peru.[15]

The FMI, developed in the late 1970s, and the Fragrance Mix II (FMII) developed in 2005, are the most valuable screening tools for the detection of delayed hypersensitivity to fragrances.[16,17] Indeed, the components of FMI ( $\alpha$-amyl cinnamaldehyde, cinnamaldehyde, cinnamic alcohol, eugenol, isoeugenol, geraniol, hydroxycitronellal and the natural extract oak moss) and FMII (hidroxyisohexyl 3 -cyclohexene carboxaldehyde, citral, $\alpha$-hexyl-cinnamadehyde, citronellol, farnesol and coumarin) are the most common skin sensitizers identified as responsible for delayed type allergic contact dermatitis to fragrances. Consequently, clinical relevance to these chemicals must be carefully examined because individuals may develop simple NICoU or $\mathrm{CoU}$ associated with delayed hypersensitivity. Chemical structures of FMI and FMII ingredients are shown in Fig. 2.

Safford et al. conducted a study on 20 patients positive to the FMI in 48 hours and classified the FMI ingredients according to the decreasing ability to induce $\mathrm{CoU}$ as follows: cinnamaldehyde, cinnamic alcohol, isoeugenol, hydroxycitronellal and geraniol.[18] Cinnamaldehyde and cinnamic alcohol were the strongest urticaria inducers for non-allergic patients. 
$\mathrm{CoU}$ from cinnamaldehyde has been reported by several authors [3], leading even to anaphylaxis.[19] Among the many components of balsam of Peru, cinnamaldehyde is described as well as the strongest agent inducing NICoU, followed by cinnamic acid, benzoic acid and benzaldehyde.[20]

Balsam of Peru is derived from the sap of Myroxylon pereirae (MP) tree. It is composed of 250 constituents, of which 189 are of known chemical structure.[21] MP has been used in topical medicaments for its antibacterial properties, and in many countries it has been abandoned for that use due to its sensitizing potential. However, it may still occur in natural and herbal products, being used as a flavor or perfume ingredient. Extracts and distillates of MP are still used in perfumes.[22] It is thus possible that these can cause allergic reactions in MP sensitized individuals.

Cinnamaldehyde is the main component of cassia oil (ca. 90\%) and cinnamon bark oil (ca. 75\%). It is also the main component of artificial cinnamon oil. Smaller quantities are found in many other essential oils. In nature, the trans isomer is predominant. It is a yellowish liquid with a characteristic spicy odor, strongly reminiscent of cinnamon. Being an $\alpha, \beta$-unsaturated aldehyde, it undergoes many reactions of which hydrogenation to cinnamic alcohol. Its oxidation occurs readily on exposure to air yielding cinnamic acid. Cinnamic acid has been also used in perfumery, as a flavoring ingredient in pharmaceutical preparations and in food products. Forsbeck and Skog found CoU from cinnamic acid $5 \%$ in petrolatum in three out of five patients with immediate skin reactions to balsam of Peru.[20]

Geraniol is an olefinic terpene mainly present in palmarosa, geranium and rose oils. It is a colorless liquid, with a flowery-roselike odor. A case of a patient with $\mathrm{CoU}$ from geraniol has been reported to be caused by immunological mechanisms. The patient developed widespread urticaria and flare reactions on the face and neck at the 72 hours reading of the patch test.[23] Oxidation processes produce aldehydes geranial and neral, and in addition, hydroperoxides. Autoxidation greatly influences the sensitizing effect of geraniol, becoming a potent allergen.[24]

Eugenol and isoeugenol are phenylpropene compounds. Eugenol is the main component of several essential oils; clove leaf oil and cinnamon leaf oil may contain $>90 \%$. It occurs in small amounts in many other essential oils. It is a colorless to slightly yellow liquid with a spicy, clove odor. It is widely used in dental practice to relieve pain arising from various sources, such as pulpitis and dentinal hypersensitivity. It is also used in toothache drops, mouthwash, and antiseptics. Eugenol in dental preparations has been reported to cause $\mathrm{CoU}$, gingivitis, stomatitis venenata and allergic hand eczema in dental personnel.[25,26] It is considered to be a less common sensitizer than isoeugenol, cinnamaldehyde or cinnamic alcohol. Isoeugenol occurs in many essential oils, mostly with eugenol, but not as the main component. Commercial isoeugenol is a mixture of cis and trans isomers, in which the thermodynamically more stable trans isomer dominates. It is a yellowish, viscous liquid with a fine clove odor. Isoeugenol is a strong allergen.[27] It caused contact allergy in $1.7 \%$ of 2261 consecutive tested eczema patients in an European multicenter study.[28] It is found in many cosmetic products and may be present in relative highly concentrations. 
Coumarin is an aromatic lactone naturally occurring in Tonka beans and other plants, determining for example the odor of woodruff. It is widely used in fine fragrances for spicy green notes. Considered for long time a sensitizer, impurities have been blamed for the sensitizing effect.[29]

Fragrances and cosmetic products contain also ingredients other than odorant compounds that have been described to produce NICoU and ICoU. Among them, benzophenone, polysorbates, sorbitan sesquiolate, propylene glycol and wool alcohols.

Benzophenones are photo-screen agents used in sunscreens and cosmetics, such as antiaging creams, hair sprays and shampoos, paints and plastics. Benzophenones have been documented to cause numerous adverse cutaneous reactions, including contact and photo-contact dermatitis, contact and photocontact urticaria, and anaphylaxis. In recent years they became particularly well known for their ability to provoke allergy and photoallergy.[30] They were named the American Contact Dermatitis Society's Allergen of the Year for 2014. CUS at stage IV has been reported in the case of people applying sunscreen and self-tanning products, being benzophenone-3 the major cause.[31] Benzophenone-3, also named oxybenzone, is often incorporated into sunscreen formulations to offer enhanced UVA protection because its absorption spectrum extends to less than $350 \mathrm{~nm}$. Cases of anaphylaxis from topical application of benzophenone-3 have been published. The cases resulted in a generalized wheal and flare reactions and syncope after widespread application of a sunscreen or sunless tanning product with this filter. CoU developed after more limited exposure.[31,32]

Polysorbates are a class of emulsifiers used in some pharmaceuticals and food preparations. But they are also often used in cosmetics to solubilize essential oils into water-based products. Oily liquids, they derive from esterification of ethoxylated sorbitan with fatty acids. The nomenclature used for polysorbates is characteristic. For example, polysorbate 80 , also called polyoxyethylene 20 sorbitan monooleate. The number 20 following the 'polyoxyethylene' part refers to the total number of oxyethylene - $\left(\mathrm{CH}_{2} \mathrm{CH}_{2} \mathrm{O}\right)$ - groups found in the molecule. The number following the 'polysorbate' part is related to the type of fatty acid associated with the polyoxyethylene sorbitan part of the molecule. Monolaurate is indicated by 20, monopalmitate by 40 , monostearate by 60 and monooleate by 80 . Already in the 70s, Maibach and Conant reported an urticaria case to polysorbate 60 in a male patient with redness on the forehead when applying hydrocortisone $1 \%$ cream.[33] The chemical responsible in the cream was determined to be polysorbate 60 , an emulsifying agent mixture of estearate esters of sorbitol and sorbitol anhydrides, consisting mainly on the monoester. It is also known as Tween 60 or polyoxoethylene 20 sorbitan monostearate. Since then, several cases have continued to be reported. More recently, a biologic-induced urticaria due to polysorbate 80 in a psoriasis treatment in Spain has been reported.[34] Sorbitan sesquiolate, a sorbitol-based emulsifier, is actually added to the FMI ingredients to constitute the mixture. Sorbitol-based emulsifiers are commonly used in topical corticosteroids, topical antibiotics and antifungals, moisturizing creams and lotions. Contact dermatitis from sorbitol derivatives appears to be increasingly prevalent.[35] This trend goes hand-in-hand with the ICoU to sorbitan sesquiolate reported in a corticosteroid ointment.[36] 
Propylene glycol, also called propane-1,2-diol, is a viscous colorless alcohol (chemically classed as a diol), nearly odorless but possessing a weak sweet taste. It is mainly used for the production of unsaturated polyester resins. It is also used as a humectant food additive (E1520), hygroscopic compound used to keep products moist, as a moisturizer in cosmetics, food, toothpaste, mouth wash and tobacco products, as the main ingredient in deodorant sticks, as an antifreeze liquid and as a solvent in many pharmaceuticals and topical formulations. Propylene glycol is one of the major ingredients of the cartridges used in electronic cigarettes where it is aerosolized in the atomizer. It has been associated with irritant and allergic contact dermatitis as well as CoU in humans. These sensitization effects can be manifested at propylene glycol concentrations as low as 2\%.[37] Still, the Cosmetic Ingredient Review Panel found that propylene glycol is safe if used in cosmetic products at concentrations not exceeding 50\%.[38] The above cited work of Maibach and Conant describing an urticaria case to polysorbate 60 concerned a hydrocortisone cream containing propylene glycol.[33] $\mathrm{CoU}$ could not be concluded in experiments with open propylene glycol application. Only one report describes NICoU after topical application.[39,40]

Wool alcohols are the principle component of lanolin. Lanolin is a natural product obtained from the fleece of sheep. Sebum is extracted from the wool, cleaned and refined to produce anhydrous lanolin. This comprises wool alcohols, fatty alcohols and fatty acids. Currently wool alcohols are considered the main sensitizers in lanolin. Wool alcohols, wool fat, anhydrous lanolin, lanolin alcohol, wool wax and wool grease are just some of the terms used interchangeably with lanolin. Lanolin is a good emulsifier. This means it binds well with water thus it is particularly useful in the manufacture of pharmaceutical and cosmetic formulations. Wool alcohols are found in many pharmaceutical preparations, cosmetics and toiletries. They also have some industrial uses. The general incidence of lanolin allergy in consecutively tested eczema patients is around 2-3\%.[41]

\section{Biocides and Preservatives}

Preservatives are added to water-containing products (i.e. cosmetics) to inhibit the growth of nonpathogenic and pathogenic microorganisms, which may cause degradation of the product or be harmful to the consumer. After fragrances, they are the most important cause of allergic contact dermatitis, being this very well-documented.[42] $\mathrm{CoU}$ is less common. The literature consists essentially of case reports, and studies on actual incidence and prevalence are lacking.

Chemicals with preservative properties that are worth to describe in the CoU context are described here. It is not always clear, depending on the underlying mechanisms involved, if the reactions are involving the immune system or not. Chemical structures are shown in Fig. 3.

Sorbic acid, or 2,4-hexadienoic acid, is a colorless solid slightly soluble in water. It is an antimicrobial agent often used as preservative in food and drinks (E200). In general the salts (sodium, potassium and calcium sorbates, E201-203) are preferred over the acid form because they are more 
soluble in water, but the active form is the acid. CoU from sorbic acid is thought to be rare, but few reports can be found in the literature. Some authors described that creams and shampoos containing sorbic acid caused erythema, slight itching and oedema sometimes.[43-45] Like sorbic acid, benzoic acid is a natural preservative, having antibacterial and antifungal properties. It is well-recognized to cause NICoU with concentration-dependent reactions.[46] Present also in balsam of Peru, it induced $\mathrm{CoU}$ at $5 \%$ in patients with immediate contact reactions to balsam of Peru.[20] It is commonly used also as a preservative in acidic food products. Thus, cases have been reported in were food additives and benzoic and sorbic acids elicit NICoU at concentrations in use in salad dressings or other food products.[47,48]

Formaldehyde $(\mathrm{HCHO})$ and its releasers constitute an important class of preservatives in consumer goods. HCHO is the simplest of the aldehydes category of compounds. It is a frequent and potent sensitizer and a strong-ubiquitous allergen, including from non-cosmetics sources of contact. Its bactericidal and fungicidal properties confer it a place of choice for preservation of cosmetics, but its use has been reduced because of the bad press it has as an irritant, sensitizer and carcinogen.[49] Exposure to $\mathrm{HCHO}$ in the EU is thus subjected to restrictions. Free HCHO may be used as a preservative in all cosmetic products (maximum authorized concentration $0.2 \%$, except $0.1 \%$ in products for oral hygiene) except aerosol cosmetics. EU regulation 1223/2009 permits the use in nail hardeners up to a maximum concentration of 5\%. Annex VI of the Cosmetics Directive 76/768 EC further stipulates that all finished products containing $\mathrm{HCHO}$ or substances that release it must be labelled with the warning "contains formaldehyde" where the concentration of free $\mathrm{HCHO}$ in the finished product exceeds $0.05 \%$.[50] On January 1st 2016, the EU officially adopted its reclassification under the CLP (Classification, Labelling and Packaging) Regulations EC 1272/2008, as a Class 1B carcinogen and Class 2 mutagen. In order to continue to be used in cosmetics the criteria specified for CMR 1A and 1B must be met, including the Scientific Committee on Consumer Safety (SCCS) to declare it safe for use in cosmetic products. The SCCS has published recently an opinion that states that nail hardeners with a maximum concentration of $2.2 \%$ free $\mathrm{HCHO}$ can be used. Even if it is a strong sensitizer, reported immediate reactions to $\mathrm{HCHO}$ are mainly classified as NICoU because they seem not to be mediated by IgE.[50] However, there is still no consensus in the reports that have appeared as to whether the mechanism is immunological or non-immunological.[51] Most literature on generalized urticaria, respiratory compromise, and anaphylaxis concerns exposure to HCHO-containing disinfectants used for root canals and other dental procedures.[52,53]. There have been few reports on allergy to $\mathrm{HCHO}$ associated with IgE, and single cases of HCHO-specific IgE mediated urticaria exist in the literature.[52-54] Thus, probably HCHO should be classified as a substance that shows mixed features of NICoU and ICoU, as the mechanism remains unclear.

As an alternative to the use of $\mathrm{HCHO}$, chemical compounds that slowly release it in the presence of water and under usage conditions, the so-called formaldehyde-releasers, are commonly employed as preservatives in cosmetics (water based preparations) instead of free HCHO. Examples are bronopol 
and imidazolidinyl urea. Unfortunately, many formaldehyde-releasers used in cosmetics are also skin sensitizers, due to released $\mathrm{HCHO}$ but also to reactive intermediates other than $\mathrm{HCHO}$ that could be involved in the formation of the hapten-protein antigenic complex, a key step of the sensitization process, and thus explaining their sensitizing potential per se.[55]

Methylisothiazolinone (MI) and methylchloroisothiazolinone (MCI) are the active ingredients of the biocide Kathon $^{\circledR} \boldsymbol{C G}$ (MI/MCI 1:3 combination), used since the 1980s and one of the most common sources of allergic contact dermatitis caused by preservatives.[56,57] Following the introduction in the EU of a $15 \mathrm{ppm}$ use limit in cosmetics, contact allergy to MI/MCI significantly decreased to a prevalence rate of about $2 \%$ after the 90 s. The sensitizing potential of the mixture was mostly attributed to the chlorinated derivative MCI, shown to be the stronger sensitizer, while the non-chlorinated MI was reported to be a much weaker allergen. Thus, in the early 2000s, MI alone started to be used as preservative in industrial products and in 2005 in cosmetics, but at higher concentrations than in the MI/MCI mixture due to its lower biocide potential. As a consequence, over recent years there has been an alarming increase in the prevalence of allergic contact dermatitis to MI.[58,59] Occupational cases of contact dermatitis to MI started to be reported from paints [60], followed by non-occupational cases essentially seen from wet wipes for hygiene and cosmetics.[61] Severe cases of airborne and systemic dermatitis have appeared recently from exposure to MI present particularly in water based wall paints.[62] At the same time, MI/MCI contact allergy has increased significantly over the past few years.[63] It has been proposed that the rise in MI/MCI contact allergy was likely linked to the higher consumer exposure to MI, and was most probably due to a previous sensitization of individuals to MI. Because the occurrence of consumer products containing only MI since few years, questions were raised about the MI and MCI cross-reaction pattern. Studies of chemical reactivity in situ in a reconstructed human epidermis model showed that reaction mechanisms for MI and MCI were different, making it difficult to explain cross-reactivity.[64] $\mathrm{CoU}$ cases caused by isothiazolinones are rare and are generally classified as NICoU.[65]

$\mathrm{CoU}$ to other biocides such as benzyl alcohol, 2-phenoxyethanol and polyethylene glycols, used as preservatives in a wide number of cosmetics and topical preparations, has also been reported.[66-69] $\mathrm{CoU}$ from alcohols was reviewed in the 90s, with cases classified as non-immunological and some as immunological based on open skin tests.[70]

Other important biocides have been correlated to ICoU such as parabens, and many antiseptics such as mercurochrome, chloramine, chlorhexidine and chlorocresol.

Parabens (methyl, ethyl, propyl, butyl) are a series of parahydroxybenzoates or esters of parahydroxybenzoic acid (also known as 4-hydroxybenzoic acid). Parabens are effective preservatives in many types of formulas, especially in cosmetic products. They are also used as food additives. In individuals with normal skin, parabens are, for the most part, non-irritating and non-sensitizing. Routine testing in the European standard series yields low prevalence rates of sensitization. [71,72] At the usual concentration of $0.1-0.3 \%$ in cosmetics, parabens rarely cause adverse reactions. They have 
been reported to cause localized $\mathrm{CoU}$ when applied to the skin and an $\mathrm{IgE}$ immune-mediated mechanism is suspected.

Mercurochrome is the trade name of merbromin, an organomercuric disodium salt and a fluorescein, used as topical antiseptic. Due to the high toxicity of mercury, it is no longer sold in the US from 1998 and in France from 2006. Mercurial compounds are known as causing allergic contact dermatitis and immediate hypersensitivity is rarely induced. Few cases have been reported were immediate hypersensitivity to mercuric fluorescein compounds has been proved by skin test and histamine liberation.[73,74]

Chloramines are derivatives of ammonia by substitution of one, two or three hydrogen atoms with chlorine atoms. Monochloroamine (commonly called chloramine) is an inorganic compound with the formula $\mathrm{NH}_{2} \mathrm{Cl}$. Chloramine is commonly used as a sterilizer, disinfectant and chemical reagent. It has been described as an occupational hazard for pharmaceutical workers, nurses and cleaners. Goossens et al. reported the first case of immediate positive epicutaneous tests to chloramine powder solutions used by a nurse.[75] All skin tests performed on the patient were suspicious of an immediate type reaction. The immunological nature of the clinical manifestations was investigated by RAST on serum of the patient. High levels of IgE antibodies to chloramine were found, those previously bound to human serum albumin (HSA). The clinical manifestation on the patient was confirmed by radioimmunoassay and classified as a stage 3 CUS. Chloramine is often confused with chloramine-T as both are employed as sterilizer, antiseptic and disinfectant agents. However, they are two different chemicals. Chloramine$\mathrm{T}$ is a $\mathrm{N}$-chlorinated deprotonated sulfonamide, white powder, contrarily to chloramine, a simple monochlorinated amine which is a colorless liquid usually handled as a diluted aqueous solution. Allergic asthma caused by chloramine- $\mathrm{T}$ is well known and the reactions are IgE mediated. Kramps et al. were able to demonstrate the presence of specific IgE antibodies in the serum of asthmaticchloramine $\mathrm{T}$ allergic patients.[76] However, skin symptoms of IgE dependent CoU have also been reported in the case of a hospital bath attendant in Finland. The performed RAST to chloramine-T showed specific IgE antibodies with values being defined as positive.[77]

Chlorhexidine is a synthetic chlorophenyl-bis-biguanide compound, containing two chloroguanide chains linked by a hexamethylene chain. It is a strong base and a dication at physiological $\mathrm{pH}$. Usually insoluble in water, it needs to be formulated with gluconic or acetic acid to form water-soluble digluconate or diacetate esters. Chlorhexidine, especially as digluconate ester, is widely used in many dental topical applications (toothpaste, dental gel, mouthwash solutions) as it binds oral mucosa inhibiting dental plaque formation. It is also used as disinfectant and antiseptic of minor cuts and wounds. It can cause both type I immediate allergy and type IV delayed allergy. In spite its common usage the sensitization rate seems low, but this is certainly underestimated. It may induce immediatetype sensitivity reactions either by topical application or by insertion of coated catheters in surgical fields. The mechanism suspected is an IgE-mediated pathomechanism in sensitized individuals.[78] Many health care workers are exposed to hand washes containing chlorhexidine. In the United Kingdom, four cases of occupational IgE-mediated allergy to chlorhexidine were identified, the 
diagnosis being made on an appropriate clinical history with positive serum specific IgE to chlorhexidine and/or positive skin prick testing.[79] The main aspects of chlorhexidine toxicity have been reviewed.[80]

Chlorocresol ( $p$-chlorocresol) is a chlorinated phenol used as an antiseptic and preservative. It forms colorless crystals at room temperature and is slightly soluble in water. For medical use it is dissolved in alcohol combined with other phenols. Several case reports involve chlorocresol as a cause of $\mathrm{CoU}$ but whether this occurs through an immunological mechanism is not clear.[81,82]

\section{Drugs}

Drugs, small reactive chemicals, can induce both NICoU and ICoU within minutes to one hour after exposure. They include mainly antibiotics, because direct contact of nurses and health care personnel during their preparation, or employees during the production in the pharmaceutical industry. Penicillins and cephalosporins are the most incriminated (Fig. 4.). All of them seem to have an immunological physiopathology and will be discussed below. For most of the other drugs reported, observed immediate contact reactions cannot be definitely classified as non-immunological or immunological. Often, skin tests do not allow distinguishing between an IgE dependent reaction and a non-specific histamine release, and research of specific IgE by using the radioallergosorbent test (RAST) is only available for some drugs. One example is given by lidocaine.

Lidocaine is a common amino amide-type local anaesthetic applied topically. It is also an antiarrhythmic drug applied intravenously. An immediate positive patch test and prick test demonstrated its involvement in the simultaneous presence of $\mathrm{CoU}$ and allergic contact dermatitis in the same patient.[83,84]

Ketoprofen ((RS)-2-(3-benzoylphenyl)-propionic acid), an important cause of photocontact dermatitis, has also been described as responsible for CoU.[85] It is one of the propionic acid class of non steroidal anti-inflammatory drugs (NSAID) with analgesic effects.

Other immediate reactions have been observed in personnel of psychiatry services during the manipulation of phenothiazines, antipsychotic drug related to the thiazine class of heterocyclic compounds, such as chlorpromazine and promethazine. The latter is a first-generation antihistamine of the phenothiazine family. It is a chiral compound and is found as a mixture of enantiomers. Among the many professional areas where case reports of $\mathrm{CoU}$ have been reported, workers of pharmaceutical and chemical industries are of considerable concern. They are in contact with highly reactive substances (some listed in Table 1) used for synthesis for example that have been also described as inducers of immediate skin reactions. The pathogenesis of NICoU to all these chemicals is not clearly defined. Different urticariogens may act by different mechanisms. For example, dimethyl sulfoxide can both damage blood vessels and cause mast cell degranulation. However, antihistamines do not inhibit reactions to dimethyl sulfoxide and other NICoU triggering agents, whilst acetylsalicylic acid and non- 
steroidal anti-inflammatory drugs do, both orally and topically, suggesting a role for prostaglandins.[86]

However, main drugs responsible for occupational $\mathrm{CoU}$ are antibiotics and, particularly, penicillin, ampicillin, amoxicillin, and cephalosporins. Antibiotics are very often associated to ICoU.[87]

The term penicillin is often used to refer to benzylpenicillin (penicillin $\mathrm{G}$, found in 1928), procaine benzylpenicillin, benzathine benzylpenicillin and phenoxymethylpenicillin. The core of the molecule has the formula $\mathrm{R}-\mathrm{C}_{9} \mathrm{H}_{41} \mathrm{~N}_{2} \mathrm{O}_{4} \mathrm{~S}$, where $\mathrm{R}$ is a variable side chain that differentiates the penicillins from one another. The key structural feature is the four-membered $\beta$-lactam ring, essential for antibacterial activity. Thus, all penicillin antibiotics contain a common nucleus (6-aminopenicillanic acid) composed of a $\beta$-lactam ring fused with a thiazolidine ring, this complex connected to a side chain. An intact $\beta$ lactam ring is necessary for bactericidal activity, and the side chain determines the spectrum of antibacterial activity, the susceptibility to destruction when exposed to acids and $\beta$-lactamases, and pharmacokinetics properties. Allergic reactions are estimated to occur in approximately $2 \%$ of patients treated with penicillin. Severe reactions to penicillin such as anaphylaxis can occur and are potentially life threatening. Penicillin is a hapten and becomes immunogenic only when it binds to a protein. The $\beta$-lactam ring covalently binds to lysine residues of proteins and forms the penicilloyl group, known as the "major determinant" because it is the major penicillin metabolic product. Penicillin metabolites also form disulfide bonds with sulfhydryl groups of cysteine, producing the "minor determinants", so called because they are formed in smaller quantities. Thus, immediate allergic reactions to penicillin are mediated through IgE antibodies against either the major or minor determinants or both. Based on this, penicillin skin testing techniques have been developed demonstrating the presence or absence of specific IgE antibodies against major and minor determinants. The use of benzylpenicilloyl-poly-Llysine can test IgE antibodies against major determinants. Histamine is used as a positive control, and saline is used as a negative control. Skin detection of serum IgE specific for major penicillin determinants has a high positive predictive value but fails to identify patients with penicillin allergy. It has been suggested that, ideally, skin testing to major and minor penicillin determinants would improve diagnosis. Methods of preparation of reagents for minor determinants have been published, and penicillin $\mathrm{G}$ has been used as a partial source of minor determinants. Alternatives to benzylpenicilloylpoly-L-lysine and minor determinant mixtures are commercially available for skin testing.[88] Penicillin skin testing is believed to be safe if done properly, although severe reactions such as anaphylaxis have been reported, these were produced because violation of the test protocols such as doing intracutaneous testing without first doing prick testing.

After penicillins, cephalosporins are the most important $\beta$-lactams inducing IgE mediated reactions.[89] Allergy has been reported with use of a specific cephalosporin, as a cross-reaction between different cephalosporins or as a cross-reaction to other $\beta$-lactam antibiotics. Unlike determinants derived from penicillins, cephalosporin allergenic determinants have not been well 
identified and thus, standardized diagnostic skin testing is not available. Nevertheless, skin testing with diluted solutions of cephalosporins can be valuable in confirming IgE-mediated hypersensitivity reactions.[90,91]

Pyrazolone is a five-membered ring lactam. It is a derivative of pyrazole that has a keto $(=\mathrm{O})$ group. There are three isomers, 3, 4 and 5-pyrazolone. Pyrazolones are NSAIDs and the most frequent drugs inducing selective reactions thought to be mediated by specific IgE. Sensitivity of diagnostic tests is poor probably due to the incomplete knowledge of the structures involved. Research is today ongoing on pyrazolone metabolites and its relevance on hypersensitivity reactions.[92]

Steroids are organic compounds with four rings arranged in a specific molecular configuration. The core structure is composed of 17 carbon atoms, bonded in four fused rings: 3 cyclohexane rings (A, B, C) and one cyclopentane ring (D). Steroids vary by the functional group attached to this core and by the oxidation state of the rings. Corticosteroids (i. e. cortisol or hydrocortisone) are potent antiinflammatory and immunomodulator agents used in treatment of various inflammatory diseases including allergic diseases. They can in some cases induce immediate or delayed hypersensitivity reactions. Topical corticosteroids are well-known contact sensitizers. However, diagnosing an allergic reaction is still a challenge for clinicians. While knowledge of delayed hypersensitivity as a secondary effect of topical use is improving, little is known about immediate reactions to systemic corticosteroids.[93] Urticaria to hydrocortisone cases have been reported, in atopic patients after hydrocortisone injection or infusion, and in patients treated with hydrocortisone sodium succinate. All cases are thought to be IgE-mediated.[94,95]

\section{Other Chemicals}

Chemicals not belonging to the families of compounds described above but necessary to mention are shown in Fig. 5.

Epoxy resins are LMW pre-polymers, which normally contain at least two epoxide groups. The epoxide group is also known as glycidyl or oxirane group. Cyclic acid anhydrides are synthetic highly reactive LMW compounds widely used as curing agents for epoxy resins and in the production of polyester resins. Commonly used anhydrides are phthalic, tetrahydrophthalic, methyl tetrahydrophthalic, hexahydrophthalic, methyl hexahydrophthalic, maleic and trimellitic anhydrides. Cyclic acid anhydrides often cause allergic respiratory diseases, and in the literature only single case reports of $\mathrm{CoU}$ of few patients were found. However, occupational $\mathrm{CoU}$ has been described by a Finnish study as workers may be exposed in powder or liquid form during manufacturing processes.[96] Data are presented for 21 subjects who had been exposed to organic acid anhydrides and examined during the period 1990-2006. The majority of the patients had been exposed to an epoxy resin containing methyl hexahydrophthalic anhydride. Specific IgE results were in line with the prick tests and the large reaction was seen for the acid anhydride the patient had been exposed to. Phthalic anhydride $\operatorname{IgE}$ was positive in 19 of 20 patients. 
Another important constituent of epoxy resins that has been incriminated as producing immediate reactions is bisphenol $\boldsymbol{A}$. It is an organic synthetic compound belonging to the diphenylmethane derivatives group and bisphenols, with two hydroxyphenyl groups. It is a colorless solid soluble in organic solvents, but poorly soluble in water. Specific IgE cases have been reported.[97,98]

Acrylates are the salts, esters and conjugated bases of acrylic acid and its derivatives. They are common monomers (i. e. methyl methacrylate) in polymer plastics. Acrylates easily form acrylate polymers due to the high reactivity of the constituting double bonds. Monomers such as 2-ethylhexyl acrylate, acrylic acid, cyanoacrylates and methyl methacrylate have been reported to cause immediate skin reactions.[99]

Aromatic amines are a broad group of chemicals used in a variety of applications, such as hair dyes, ink for printers, photographic products, paper and textile industries, among others. According to their large spectrum of application, skin exposure of the general population to these compounds is high. Safety aspects and toxicity studies have shown that para-amino aromatic compounds and their derivatives are strong skin sensitizers, generally related to dyeing products. One of the most known is para-phenylenediamine (PPD). PPD is one of the most common primary intermediates of oxidative hair dyes and is usually reported as the main sensitizer in hair dye dermatitis. PPD is therefore included in the European Standard Series for diagnostic patch testing of eczema patients and is generally regarded as the screening agent for contact allergy to para-amino aromatic compounds but also to azo aromatic compounds used in textile dyes.[100-102] It can also induce immediate-type reactions going from local urticaria to fatal systemic reactions and anaphylactic shock.[103-105]

Other chemical compounds of LMW reported as inducing ICoU are aliphatic polyamides, methyl ethyl ketone, widely used as solvent in plastic manufacture, and monoamylamine, a vehicle ingredient of topical medicaments. Also, benzonitrile, a useful solvent and versatile precursor to many derivatives, carbamate-constituting groups of polyureythanes and diethyl fumarate.

Finally, metals and metallic salts can also cause occupational CoU. Aluminum, chromium, cobalt, iridium salts, nickel, platinum salts and rhodium have been reported. Among them, platinum salts are important allergens in the catalyst industry and clinical manifestations may involve both the respiratory system and the skin.[106-111] 


\section{REFERENCES}

1. Giménez-Arnau A, Maurer M, De la Cuadra J, Maibach HI. Immediate contact skin reactions, an update of contact urticaria, contact urticaria syndrome and protein contact dermatitis-"A never ending story". Eur J Dermatol. 2010; 20: 552-562.

2. Ale SI, Maibach HI. Occupational contact urticaria. In: Kanerva L, Elsner P, Wahlberg JE, Maibach HI, editors. Handbook of Occupational Dermatology. Berlin: Springer-Verlag, 2000: p. 200-216.

3. Lahti A. Non-immunologic contact urticaria. Acta Dermatovener (Stockholm). 1980; 60 (Suppl. 91): 1-49.

4. Kligman AM. The spectrum of contact urticaria: wheals, erythema and pruritus. Dermatologic Clin. 1990; 8: 57-60.

5. Coverly J, Peters L, Whittle E, Basketter DA. Susceptibility to skin stinging, non-immunologic contact urticaria and skin irritation-is there a relationship? Contact Dermatitis. 1998; 38: 90-95.

6. Lahti A, Vaananen A, Kokkonen E-L, Hannuksela M. Acetylsalicylic acid inhibits nonimmunologic contact urticaria. Contact Dermatitis. 1987; 16: 133-135.

7. Johansson J, Lahti A. Topical non-steroidal anti-inflammatory drugs inhibit non-immunological immediate contact reactions. Contact Dermatitis. 1988; 19: 161-165.

8. Wakelin SH. Contact urticaria. Clin Exp Dermatol. 2001; 26: 132-136.

9. Amaro C, Goossens A. Immunological occupational contact urticaria and contact dermatitis from proteins: a review. Contact Dermatitis. 2008; 58: 67-75.

10. Goossens A, Amaro C, Géraut C. Urticaire et dermatite de contact aux protéines en pathologie professionnelle. In : Progrès en Dermato-Allergologie. Paris: John Libbey Eurotext, 2007: p. 5770.

11. Castanedo-Tardan MP, Jacob SE, Baumann LS. Contact urticaria to cosmetic and toiletry ingredients. Cosmetic Dermatol. 2008; 21: 339-346.

12. Lahti A, Basketter D. Immediate contact reactions. In: Johansen JD, Frosch PJ, Lepoittevin J-P, editors. Contact Dermatitis, 5" edn. Berlin: Springer-Verlag, 2011: p. 137-153.

13. Gleich GJ, Yunginger JW. The radioallergosorbent test: a method to measure IgE antibodies, IgG blocking antibodies, and the potency of allergy extracts. Bull N Y Acad Med. 1981; 57: 559-567.

14. Vigan M. Urticaire de contact aux cosmétiques. In: Progrès en Dermato-Allergologie. Paris: John Libbey Eurotext, 2007: 17-34.

15. Cancian M, Fortina AB, Peserico A. Contact urticaria syndrome from constituents of balsam of Peru and fragrance mix in a patient with chronic urticaria. Contact Dermatitis. 1999; 41: 3000.

16. Larsen WG. Perfume dermatitis. A study of 20 patients. Arch Dermatol. 1977; 113: 623-627.

17. Frosch PJ, Pirker C, Rastogi SC, Andersen K, Bruze M, Svedman C, Goossens A, White IR, Uter W, Giménez-Arnau E, Lepoittevin J-P, Menné T, Johansen JD. Patch testing with a new fragrance mix detects additional patients sensitive to perfumes and missed by the current fragrance mix. Contact Dermatitis. 2005; 52: 207-215.

18. Safford RJ, Basketter DA, Allenby CF, Goodwin BFJ. Immediate contact reactions to chemicals in the fragrance mix and a study of the quenching action of eugenol. Br J Dermatol. 1990; 123: 595606.

19. Diba VC, Statham BN. Contact urticaria from cinnamal leading to anaphylaxis. Contact Dermatitis. 2003; 48: 119.

20. Forsbeck M, Skog E. Immediate reactions to patch tests with balsam of Peru. Contact Dermatitis. 1977; 3: 201-205.

21. Hausen BM, Simatupang T, Bruhn G, Evers P, Koenig WA. Identification of new allergens constituents and proof of evidence for coniferyl benzoate in balsam of Peru. Am J Contact Dermat. 1995; 6: 199-208. 
22. Api AM. Only Peru Balsam extracts or distillates are used in perfumery. Contact Dermatitis. 2006; 54: 179.

23. Yamamoto A, Morita A, Tsuji T et al. Contact urticaria from geraniol. Contact Dermatitis. 2002; 46: 52.

24. Hagvall L, Bäcktorp C, Svensson S, Nyman G, Börje A, Karlberg AT. Fragrance compound geraniol forms contact allergens on air exposure. Identification and quantification of oxidation products and effect on skin sensitization. Chem Res Toxicol. 2007; 20: 807-814.

25. Kanerva L, Estlander T, Jolanki R. Dental nurse's occupational allergic contact dermatitis from eugenol used as a restorative dental material with polymethylmethacrylate. Contact Dermatitis. 1998; 38: 339-340.

26. Praven T, Pushpalatha C, Shrenik J, Sowmya SW. An unexpected positive hypersensitive reaction to eugenol. BMJ Case Rep. 2013: doi:10.1136/bcr-2013-009464.

27. Marzulli FN, Maibach HI. Contact allergy: predictive testing of fragrance ingredients in humans by Draize and maximization tests. J Environ Pathol Toxicol. 1980; 3: 243-245.

28. Tananka S, Royds C, Buckley D, Basketter DA, Goossens A, Bruze M, Svedman C, Menné T, Johansen JD, White IR, McFadden JP. Contact allergy to isoeugenol and its derivatives: problems with allergen substitution. Contact Dermatitis. 2004; 51: 288-291.

29. Vocanson M, Valeyrie M, Rozières A, Hennino A, Floc'h F, Gard A, Nicolas JF. Lack of evidence for allergenic properties of coumarin in a fragrance allergy mouse model. Contact Dermatitis. 2007; 57: 361-364.

30. Heurung AR, Raju SI, Warshaw EM. Benzophenones. Dermatitis. 2014; 25: 3-10.

31. Emonet S, Pasche-Koo F, Perin-Minisini MJ, Hauser C. Anaphylaxis to oxybenzone, a frequent constituent of sunscreens. J Allergy Clin Immunol. 2001; 107: 556-557.

32. Yesudian PD, King CM. Severe contact urticarial and anaphylaxis from benzophenone-3 (2hydroxy-4-methoxy benzophenone). Contact Dermatitis. 2002; 46: 55-56.

33. Maibach HI, Conant M. Contact urticarial to a corticosteroid cream: polysorbate 60. Contact Dermatitis. 1977; 3: 350-351.

34. Pérez-Pérez L, García Gavín J, Piñeiro B, Zulaica A. Biologic-induced urticarial due to polysorbate 80: usefulness of prick test. Br J Dermatol. 2011; 164: 1119-1120.

35. Asarch A, Scheinmann PL. Sorbitan sesquiolate: an emerging contact allergen. Dermatitis. 2008; 19: 339-341.

36. Hardy H, Maibach H. Contact urticarial syndrome from sorbitan sesquiolate in a corticosteroid ointment. Contact Dermatitis. 1995; 32: 114.

37. EWG's Skin Deep ${ }^{\circledR}$ Cosmetics Database. http://www.ewg.org/skindeep.

38. Cosmetic Ingredient Review. http://www.cir-safety.org/ingredient/propylene-glycol.

39. Funk JO, Maibach HI. Propylene glycol dermatitis: re-evaluation of an old problem. Contact Dermatitis. 1994; 31: 236-241.

40. Andersen KE, Storrs FJ. Skin irritation caused by propylene glycols. Hautarzt. 1982; 33: 12-14.

41. Warshaw EM, Nelsen DD, Maibach HI, Marks JG, Zug KA, et al. Positive patch test reactions to lanolin: cross-sectional data from the North American Contact Dermatitis Group, 1994 to 2006. Dermatitis. 2009; 20: 79-88.

42. Lundov MB, Moesby L, Zachariae C, Johansen JD. Contamination versus preservation of cosmetics: a review on legislation, usage, infections, and contact allergy. Contact Dermatitis. 2009; 60: 70-78.

43. Fryklöf L-E. A note on the irritant properties of sorbic acid in ointments and creams. J Pharm Pharmacol. 1958; 10: 719-720.

44. Rietschel RL. Contact urticaria from synthetic cassia oil and sorbic acid limited to the face. Contact Dermatitis. 1978; 4: 347-349. 
45. Clemmensen O, Hjort N. Perioral contact urticarial from sorbic acid and benzoic acid in salad dressing. Contact Dermatitis. 1982; 8: 1-6.

46. Nair B. Final report on the safety assessment of benzyl alcohol, benzoic acid and sodium benzoate. Int J Toxicol. 2001; 20: 23-50.

47. Clemmenson O, Hjorth N. Perioral contact urticaria from sorbic acid and benzoic acid in a salad dressing. Contact Dermatitis. 1982; 8: 1-6.

48. Hannuksela M, Haahtela, T. Hypersensitivity reactions to food additives. Allergy. 1987; 42: 561575.

49. Public Health England. Formaldehyde: health effects, incident management and toxicology. 2017. https://www.gov.uk/government/publications/formaldehyde-properties-incident-management-andtoxicology.

50. Eighth Commission Directive 86/199/EC of 26 March 1986 adapting to technical progress Annexes II, IV and VI to Council Directive 76/768/EC on the approximation of the laws of the Member States relating to cosmetic products. Off J Eur Commun. 1986; L149: 38-45.

51. Von Krogh G, Maibach HI. Contact Urticaria. In: Occupational skin disease (Adam RM, ed). Grune \& Stratton, New York, 1983: 58-69.

52. Torresani C, Periti I, Beski L. Contact urticaria syndrome from formaldehyde with multiple physical urticarias. Contact Dermatitis 1996; 35: 174-175.

53. Braun J, Zana H, Purohit A. Anaphylactic reactions to formaldehyde in root canal sealant after endodontic treatment. Four cases of anaphylactic shock and three of generalized urticarial. Allergy. 2003; 58: 1210-1214.

54. Ogawa M, Nishinakagawa S, Yokosawa F, Yoshida T, Endo Y. Formaldehyde-specific IgEmediated urticaria due to formaldehyde in a room environment. Japanese $J$ of Occup Med and Traumatol. 2009; 57: 125-129.

55. Kireche M, Giménez-Arnau E, Lepoittevin J-P. Preservatives in cosmetics: reactivity of allergenic formaldehyde releasers toward amino acids through breakdown products other than formaldehyde. Contact Dermatitis. 2010; 63: 192-202.

56. Schnuch A, Lessmann H, Geier J, Uter W. Contact allergy to preservatives. Analysis of IVDK data 1996-2009. Br J Dermatol. 2011; 164: 1316-1325.

57. Thyssen JP, Engkilde K, Lundov MD, Carlsen BC, Menné T, Johansen JD. Temporal trends of preservative allergy in Denmark (1985-2008). Contact Dermatitis. 2010; 62: 272-273.

58. Gonçalo M, Goossens A. Whilst Rome burns: the epidemic of contact allergy to methylisothiazolinone. Contact Dermatitis. 2013; 68: 257-258.

59. Lundov MD, Opstrup MS, Johansen JD. Methylisothiazolinone contact allergy - a growing epidemic. Contact Dermatitis. 2013; 69: 271-275.

60. Thyssen JP, Sederberg-Olsen N, Thomsen JF, Menné T. Contact dermatitis from methylisothiazolinone in a paint factory. Contact Dermatitis. 2006; 54: 322-324.

61. García-Gavín J, Vansina S, Kerre S, Naert A, Goossens A. Methylisothiazolinone, an emerging allergen in cosmetics? Contact Dermatitis. 2010; 63: 96-101.

62. Lundov MD, Zachariae C, Menné T, Johansen JD. Airborne exposure to preservative methylisothiazolinone causes severe allergic reactions. BMJ. 2012; 345: e8221.

63. Geier J, Lessmann H, Schnuch A, Uter W. Recent increase in allergic reactions to methylchloroisothiazolinone/methylisothiazolinone: is methylisothiazolinone the culprit? Contact Dermatitis. 2012; 67: 334-341.

64. Debeuckelaere C, Moussallieh FM, Elbayed K, Namer IJ, Berl V, Giménez-Arnau E, Lepoittevin J-P. In situ chemical behaviour of methylisothiazolinone (MI) and methylchloroisothiazolinone 
(MCI) in reconstructed human epidermis: a new approach to the cross-reactivity issue. Contact Dermatitis. 2016; 74: 159-167.

65. Gebhardt M, Looks A, Hipler UC. Urticaria caused by type IV sensitization to isothiazolinones. Contact Dermatitis. 1997; 36: 314.

66. Guin JD, Goodman J. Contact urticaria from benzyl alcohol presenting as intolerance to saline soaks. Contact Dermatitis. 2001; 45: 182-183.

67. Walker SL, Chalmers RJG, Beck MH. Contact urticaria due to p-chloro-m-cresol. Br J Dermatol. 2004; 151: 927-952.

68. Birnie AJ, English JS. 2-Phenoxyethanol-induced contact urticaria. Contact Dermatitis. 2006; 54: 349.

69. Co-Minh HB, Demoly P, Guillot B, Raison-Peyron N. Anaphylactic shock after oral intake and contact urticaria due to polyethylene glycols. Allergy. 2007; 62: 92-93.

70. Ophaswongse S, Maibach HI. Alcohol dermatitis: allergic contact dermatitis and contact urticaria syndrome. Contact Dermatitis. 1994; 30: 1-6.

71. Uter W. The European Surveillance System of Contact Allergies (ESSCA): results of patch testing the standard series. J Eur Acad Dermatol Venereol. 2008; 22: 174-181.

72. Zug KA, Warshaw EM, Fowler JF, et al. Patch-test results of the North American Contact dermatitis Group 2005-2006. Dermatitis. 2009; 20: 149-160.

73. Barranco Sanz P, Martin Muñoz F, Lopez Serrano C, Martin Esteban M, Ojeda Casas JA. Hypersensitivity to mercuric fluorescein compounds. Allergol Immunopathol. 1989; 17: 219-222.

74. Corrales Torres JL, De Corres F. Anaphylactic hypersensitivity to mercurochrome (merbrominum). Ann Allergy. 1985; 54: 230-232.

75. Dooms-Goossens A, Gevers D, Mertens A, Vanderheyden D. Allergic contact urticaria due to chloramine. Contact Dermatitis. 1983; 9: 319-320.

76. Kramps JA, van Toorenenbergen AW, Vooren PH, Dijkman JH. Occupational asthma due to inhalation of chloramine-T. II. Demonstration of specific IgE antibodies. Int Arch Allergy Appl Immunol. 1981; 64: 428-438.

77. Kanerva L, Alanko K, Estlander T, Sihvonen T, Jolanki R. Occupational allergic contact urticaria from chloramine-T solution. Contact Dermatitis. 1997; 37: 180-181.

78. Sinaiko R, Heinemann C, Maibach HI. Contact urticaria and anaphylaxis to Chlorhexidine. In: Dermatotoxicology (Zhai H, Wilhelm KP, Maibach HI, eds). CRC Press, 2007: 485-495.

79. Nagendran V, Wicking J, Ekbote A, Onyekwe T, Garvey LH. Ig-E mediated chlorhexidine allergy: a new occupational hazard? Occup Med. 2009; 59: 270-272.

80. Calogiuri GF, Di Leo E, Trautmann A, Nettis E, Ferrannini A, Vacca A. Chlorhexidine hypersensitivity: a critical and updated review. J Allergy Ther. 2013; 4: 141.

81. Walker S, Chalmers R, Beck M. Contact urticaria due to $p$-chloro-m-cresol. Br J Dermatol. 2004; 151: 936-937.

82. Goncalo M, Goncalo S, Moreno A. Immediate and delayed sensitivity to chlorocresol. Contact Dermatitis. 1987; 17: 46-47.

83. Jovanovic M, Karadaglic D, Brkic S. Contact urticaria and allergic contact dermatitis to lidocaine in a patient sensitive to benzocaine and propolis. Contact Dermatitis. 2006; 54: 124-126.

84. Waton J, Boulanger A, Trechot PH, Schumtz JL, Barbaud A. Contact urticaria from Emla cream. Contact Dermatitis. 2004; 51: 284-287.

85. Suzuki T, Kawada A, Yashimoto Y, Isogai R, Aragane Y, Tezuka T. Contact urticaria to ketoprofen. Contact Dermatitis. 2003; 48: 284-285.

86. Johansson J, Lahti A. Topical non-steroidal anti-inflammatory drugs inhibit non-immunological immediate contact reactions. Contact Dermatitis. 1988; 19: 161-165. 
87. Arroliga ME, Pien L. Penicillin allergy: consider trying penicillin again. Cleveland Clinic J Med. 2003; 70: 313-326.

88. Nola RC, Puy R, Deckert K, O'Hehir RE, Douglass JA. Experience with a new commercial skin testing kit to identify IgE-mediated penicillin allergy. Int Med J. 2008; 38: 357-367.

89. Kim MH, Lee JM. Diagnosis and management of immediate hypersensitivity reactions to cephalosporins. Allergy Asthma Immunol Res. 2014; 6: 485-495.

90. Romano A, Mayorga C, Torres MJ, Artesani MC, Suau R, Sanchez F, Perez E, Venuti A, Blanca M. Immediate allergic reactions to cephalosporins: cross-reactivity and selective responses. J Allergy Clin Immunol. 2000; 106: 1177-1183.

91. Kim JE, Kim SH, Jin HJ, Hwang EK, Kim JH, Ye YM, Park HS. IgE sensitization to cephalosporins in health care workers. Allergy Asthma Immunol Res. 2012; 4: 85-91.

92. Ariza A, García-Martín E, Salas M, Montañez MI, Mayorga C, et al. Pyrazolones metabolites are relevant for identifying selective anaphylaxis to metamizole. Sci Rep. 2016; 6: 23845.

93. Brandão FM, Goossens A. Topical drugs. In: Contact Dermatitis $5^{\text {th }}$ ed. (Johansen JD, Frosch PJ, Lepoittevin J-P, eds). Springer-Verlag, 2011: 729-762.

94. Rasanen L, Tarvainen K, Makinen-Kiljunen S. Urticaria to hydrocortisone. Allergy. 2001; 56: 352353.

95. Nettis E, Muratore L, Valogiuri G, Ferrannini A, Tursi A. Urticaria to hydrocortisone. Allergy. 2001; 56: 802-803.

96. Helaskoski E, Kuuliala O, Aalto-Korte K. Occupational contact urticaria caused by cyclic acid anhydrides. Contact Dermatitis. 2009; 60: 214-221.

97. Kanerva L, Jolanki R, Tupasela O, Halmepuro L, Keskinen H, Estlander T, Sysilampi ML. Immediate and delayed allergy from epoxy resins based on diglycidyl ether of bisphenol A. Scand J Work Environ Health. 1991; 17: 208-215.

98. Kanerva L, Pelttari M, Jolanki R, Alanko K, Estlander T, Suhonen R. Occupational contact urticarial from diglycidyl ether of bisphenol A epoxy resin. Allergy. 2002; 57: 1205-1207.

99. Kanerva L, Tokannen J, Jolanki R, Estlander T. Statistical data on occupational contact urticaria. Contact Dermatitis. 1996; 35: 229-233.

100. Koopmans A K, Bruynzeel DP. Is PPD a useful screening agent? Contact Dermatitis. 2003; 48: 89-92.

101. Seidenari S, Mantovani L, Manzini BM, Pignatti M. Cross-sensitizations between azo dyes and para-amino compound. Contact Dermatitis. 1997; 36: 91-96.

102. Uter W, Geier J, Lessmann H, Hausen BM. Contact allergy to disperse blue 106 and disperse blue 124 in german and austrian patients, 1995 to 1999. Contact Dermatitis. 2001; 44: 173-177.

103. Wong GA, King CM. Immediate-type hypersensitivity and allergic contact dermatitis due to paraphenylenediamine in hair dye. Contact Dermatitis. 2003; 48: 166.

104. Sosted H, Agner T, Andersen KE, Menné T. 55 cases of allergic reactions to hair dye: a descriptive consumer complaint-based study. Contact Dermatitis. 2002; 47: 299-303.

105. Goldberg BJ, Hermnn FF,Hirata I. Systemic anaphylaxis due ton an oxidation product of pphenylenediamine in a hair dye. Ann Allergy. 1987; 58: 205-208.

106. Helgesen AL, Austad J. Contact urticaria from aluminium and nickel in the same patient. Contact Dermatitis. 1997; 37: 303-304.

107. Kreciscz B, Kiec-Swierczynska M, Krawczyk P, Chomiczewska D, Palczynski C. Cobalt-induced anaphylaxis, contact urticaria and delayed allergy I a ceramics decorator. Contact Dermatitis. 2009; 60: 173-174.

108. Bergman A, Svedberg U, Nilsson E. Contact urticaria with anaphylactic reactions caused by occupational exposure to iridium salt. Contact Dermatitis. 1995; 32: 14-17. 
109. Estlander T, Kanerva L, Tupasela O, Keskinen H, Jolanki R. Immediate and delayed allergy to nickel with contact urticaria, rhinitis, asthma and contact dermatitis. Clin Exp Allergy. 1993; 23: 306-310.

110. Cristaudo A, Sera F, Severino V, De Rocco M, Di Lella E, Picardo M. Occupational hypersensitivity to metal salts, including platinum, in the secondary industry. Allergy. 2005; 60: 159-164.

111. Schena D, Barba A, Costa G. Occupational contact urticaria due to cisplatin. Contact Dermatitis. 1996; 34: 220-221. 
TABLE 7.1

Chemical compounds reported as triggering NICoU and ICoU skin reactions $[1,12]$

\begin{tabular}{|c|c|c|c|c|}
\hline Compound Name & Product Category & NICoU & ICoU & Unclassified \\
\hline Acetic acid & Other & & & $\times$ \\
\hline Acetyl acetone & Other & & $\times$ & \\
\hline Acetylsalicylic acid & Drugs & & & $\times$ \\
\hline Acid anhydrides & Other & & $x$ & \\
\hline Acrylic acid & Other & & $x$ & \\
\hline Acrylic monomers & Other & & $\times$ & \\
\hline Aescin & Drugs & & $x$ & \\
\hline Albendazole & Drugs & & $x$ & \\
\hline Alcohols (amyl, ethyl, propyl, isopropyl, benzyl) & Biocides-Preservatives & & & $\times$ \\
\hline Aliphatic polyamide & Other & & $x$ & \\
\hline Allantoin & Fragrances-Cosmetics & & $x$ & \\
\hline Aluminium (metal) & Other & & & $\times$ \\
\hline Aminophenazone & Drugs & & & $x$ \\
\hline$p$-Aminodiphenylamine (dye) & Other & & $x$ & \\
\hline Aminothiazole & Other & & $x$ & \\
\hline Ammonia & Biocides-Preservatives & & $x$ & \\
\hline Amoxicillin & Drugs & & & $x$ \\
\hline Ampicillin & Drugs & & $x$ & \\
\hline$\alpha$-Amyl cinnamaldehyde & Fragrances-Cosmetics & $x$ & & \\
\hline Anisyl alcohol & Fragrances-Cosmetics & $x$ & & \\
\hline Aziridine & Other & & $x$ & \\
\hline Azithromycin & Drugs & & $x$ & \\
\hline Bacitracin & Drugs & & $x$ & \\
\hline Balsam of Peru & Fragrances-Cosmetics & $x$ & & \\
\hline Basic blue 99 (hair dye) & Other & & $x$ & \\
\hline Benzaldehyde & Fragrances-Cosmetics & $x$ & & \\
\hline Benzocaine & Drugs & & & $\times$ \\
\hline Benzoic acid & Biocides-Preservatives & $x$ & & \\
\hline Benzonitrile & Other & & $x$ & \\
\hline Benzophenone & Fragrances-Cosmetics & $x$ & & \\
\hline Benzoyl peroxide & Drugs & & $x$ & \\
\hline Bisphenol A & Other & & $x$ & \\
\hline Bronopol & Biocides-Preservatives & $x$ & & \\
\hline Butylated-hydroxytoluene & Biocides-Preservatives & & $x$ & \\
\hline Butylhydroxytoluol & Other & & & $x$ \\
\hline Camphor & Biocides-Preservatives & $x$ & & \\
\hline Capsaicin & Drugs & $\times$ & & \\
\hline Carbamates & Other & & & $x$ \\
\hline Cassia oil & Fragrances-Cosmetics & $x$ & & \\
\hline Cephalosporins & Drugs & & $x$ & \\
\hline Cetyl alcohol (emulsifier) & Fragrances-Cosmetics & & & $x$ \\
\hline Chloramine & Biocides-Preservatives & & $x$ & \\
\hline Chloramphenicol & Drugs & & $x$ & \\
\hline Chlorhexidine & Biocides-Preservatives & & $x$ & \\
\hline Chlorocresol & Biocides-Preservatives & $x$ & $x$ & \\
\hline Chloroform & Other & $x$ & & \\
\hline Chlorothalonil & Other & & $x$ & \\
\hline Chlorpromazine & Drugs & & & $x$ \\
\hline Chromium (metal) & Other & & $x$ & \\
\hline Cinnamaldehyde & Fragrances-Cosmetics & $x$ & & \\
\hline Cinnamic acid & Fragrances-Cosmetics & $x$ & & \\
\hline Cinnamic alcohol & Fragrances-Cosmetics & $x$ & & \\
\hline Cinnamon oil & Fragrances-Cosmetics & & & $x$ \\
\hline Cisplatin (platinum salts) & Drugs & & $x$ & \\
\hline Cobalt (metal) & Other & & $x$ & \\
\hline Colophony (plant derivative) & Other & & $x$ & \\
\hline Copper (metal) & Other & & & $x$ \\
\hline Coumarin & Fragrances-Cosmetics & $x$ & & \\
\hline Dibutylphthalate & Other & & $x$ & \\
\hline Di-(2-ethylhexyl) phthalate & Other & & $x$ & \\
\hline
\end{tabular}


Diethylfumarate

Other

Diethyltoluamine

Other

Dimethylammonium chloride

Other

Dimethyl sulfoxide

Other

Dinitrochlorobenzene

Drugs

Diphenylcyclopropenone

Drugs

Diphenylmethane-4,4'-diisocyanate

Other

Donezepil

Drugs

Epoxy resins

Eugenol

Formaldehyde

Formaldehyde resin

Fumaric acid

Gentamicyn

Geraniol

Gold (metal)

Hydroxycitronellal

Imidazolidinyl urea

Iodochlorhydroxyquin

Iridium (metal)

Isoeugenol

Kathon CG

Ketoprofen

Levopromazine

Lidocaine

Other

Fragrances-Cosmetics

Biocides-Preservatives

Other

Other

Drugs

Fragrances-Cosmetics

Other

Fragrances-Cosmetics

Biocides-Preservatives

Drugs

Other

Fragrances-Cosmetics

Biocides-Preservatives

Drugs

Drugs

Drugs

Lindane

Mechlorethamine

Menthol

Mercurochrome

Mercury (metal)

Methimazole

Methyl ethyl ketone

Mezlocillin

Monoamylamine

Neomycin

Nickel (metal)

Nicotinic acid esters

Nylon

Palladium (metal)

Panthenol (hair product)

Parabens $^{\circ}$

Penicillins

Pentamidine isothionate

Phenotiazides

2-Phenoxyethanol

$p$-Phenylenediamine (hair dye)

Phenyl mercuric acetate

Phenyl mercuric propionate

Pilocarpine

Polyethyleneglycol

Polypropylene

Polysorbates (emulsifier)

Promethazine

Propylene glycol

Propyphenazone

Pyrazolones

Pyrrolidone carboxylate

Resorcinol

Rhodium (metal)

Ruthenium (metal)

Ryfamicin

Sodium benzoate

Sodium hypochlorite

Sorbic acid

Sorbitan monolaurate (emulsifier)

Sorbitan monostearate (emulsifier) ${ }^{b}$

Drugs

Drugs

Fragrances-Cosmetics

Biocides-Preservatives

Other

Drugs

Other

Drugs

Drugs

Drugs

Other

Drugs

Other

Other

Other

Biocides-Preservatives

Drugs

Drugs

Drugs

Biocides-Preservatives

Other

Biocides-Preservatives

Biocides-Preservatives

Drugs

Biocides-Preservatives

Other

Fragrances-Cosmetics

Drugs

Fragrances-Cosmetics

Drugs

Drugs

Fragrances-Cosmetics

Fragrances-Cosmetics

Other

Other

Drugs

Biocides-Preservatives

Biocides-Preservatives

Biocides-Preservatives

Fragrances-Cosmetics

Fragrances-Cosmetics

Fragrances-Cosmetics

$\times$

$\times$

$x$

$x$

$x$

$\times$

$\times$

$x$

$x$

$x$

$\times$

$x$

$\times$

$x$

$x$

$x$

$x$

$x$

$x$

$x$

$x$

$x$

$x$

$x$

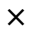

$\times$

$\times$

$x$

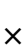

$x$
$\times$

$x$

$x$

$x$

$\times$

$x$

$x$

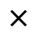

Sorbitan sesquiolate (emulsifier) 
Stearyl alcohol (emulsifier)

Steroids

Streptomycin

Sulbactam

Tin (metal)

Trichloroethanol

Turpentine (plant derivative)

Vanillin

Vinyl pyridine

Virginiamycin

Wool alcohol

Xylene

Zinc (metal)
Fragrances-Cosmetics

Drugs

Drugs

Drugs

Other

Other

Other

Fragrances-Cosmetics

Other

Drugs

Fragrances-Cosmetics

Other

Other $x$

$x$

$\times$

$x$

$x$

$\times$

$x$

$\times$

${ }^{\text {a } I m m e d i a t e ~ c o n t a c t ~ r e a c t i o n, ~ u n c l a s s i f i e d ~ n o n i m m u n o l o g i c a l / i m m u n o l o g i c a l ~}$

${ }^{\mathrm{b}}$ Described as (non-clear evidence) 


\section{FIGURE LEGENDS}

Fig. 1. NICoU and ICoU general mechanisms.

Fig. 2. Chemical structures of the components of FMI and FMII.

Fig. 3. Chemical structures of most important preservatives and biocides.

Fig. 4. Chemical structures of drugs involved in immediate skin contact reactions.

Fig. 5. Chemical structures of other LMW compounds involved in immediate skin contact reactions. 
Fig. 1.

a

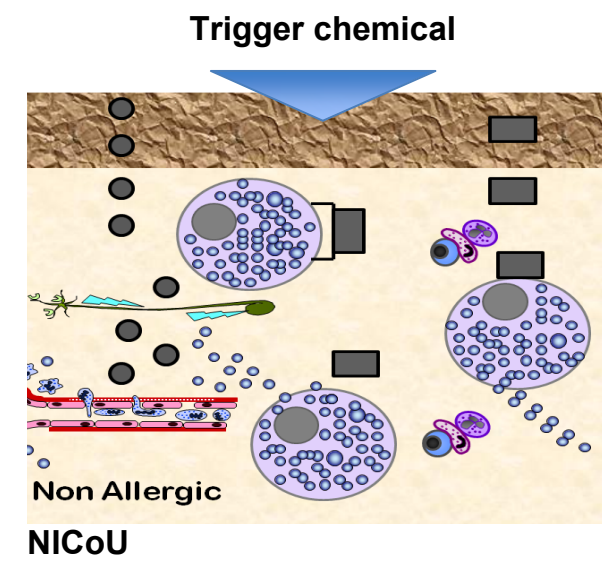

b

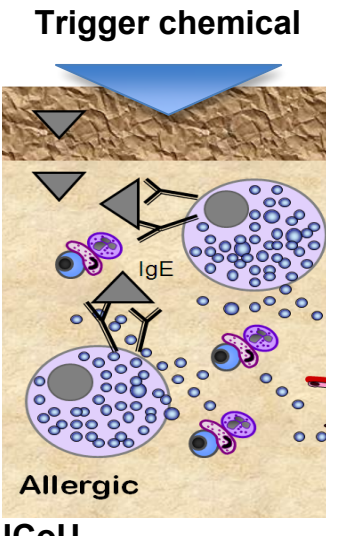


Fig. 2.

FMI<smiles>CC(CC=O)CCCC(C)(C)O</smiles><smiles>O=C/C=C/c1ccccc1</smiles><smiles>OC/C=C/c1ccccc1</smiles><smiles>CCCCC/C(=C\c1ccccc1)CO</smiles>

Hydroxycitronellal Cinnamaldehyde Cinnamic alcohol CAS [104-54-1]

$\alpha$-Amyl-cinnamic alcohol CAS [107-75-5]<smiles>CC(C)=CCCC(C)=CCO</smiles><smiles>C=CCc1ccc(O)c(OC)c1</smiles>
CAS [101-85-9]

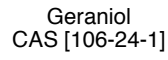

Eugenol CAS [97-53-0]

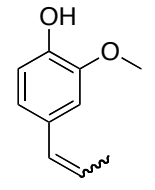

Isoeugenol CAS [97-54-1]

\section{FMII}<smiles>CC(C)(O)CCCC1=CCC(C=O)CC1</smiles><smiles>CC(C)=CCCC(C)=CC=O</smiles>
CAS [5392-40-5] carboxaldehyde $\left(\right.$ Lyral $\left.{ }^{\circledR}\right)$ CAS [31906-04-4]
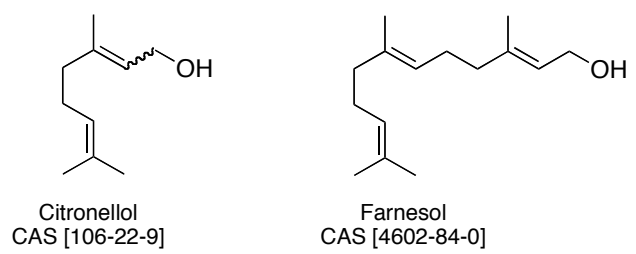

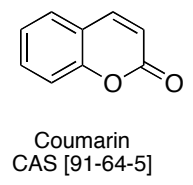

-Hexyl-cinnamaldehyde [101-86-0] CAS [91-64-5] 
Fig. 3.<smiles>C/C=C/C=C/C(=O)O</smiles>

Sorbic acid CAS [110-44-1]

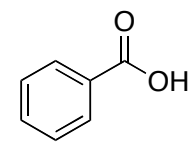

Benzoic acid CAS [65-85-0]
${ }_{H}^{\mathrm{O}}$

Formaldehyde CAS [50-00-0]<smiles>O=[N+]([O-])C(Br)(CO)CO</smiles>

Bronopol CAS [52-51-7]<smiles>O=C(NCNC(=O)NC1C(=O)NC(=O)N1CO)NC1C(=O)NC(=O)N1CO</smiles><smiles>Cn1sccc1=O</smiles><smiles>Cn1sc(Cl)cc1=O</smiles>

Methylchloro isothiazolinone CAS [26172-55-4]<smiles>OCCOc1ccccc1</smiles>

2-Phenoxyethanol CAS [122-99-6]<smiles>ClN[TlH]</smiles><smiles>[R]OC(=O)c1ccc(O)cc1</smiles>
Parabens $\mathrm{R}=\mathrm{Me}$ : CAS [99-76-3] R=Et: CAS [120-47-8] $\mathrm{H}_{\mathrm{H}}{ }^{`} \mathrm{Cl} \quad \mathrm{R}=\mathrm{Bu}$ CAS [94-26-8]<smiles>COc1c(Br)cc2c(-c3ccccc3C(N)=O)c3cc(Br)c(=O)cc-3oc2c1[Hg]O</smiles>

Chloramine CAS [10599-90-3]<smiles>Cc1cc(O)ccc1Cl</smiles><smiles>N=C(NCCCCCCNC(=N)NC(=N)Nc1ccc(Cl)cc1)NC(=N)Nc1ccc(Cl)cc1</smiles>

p-Chlorocreso CAS [59-50-7] 
Fig. 4.
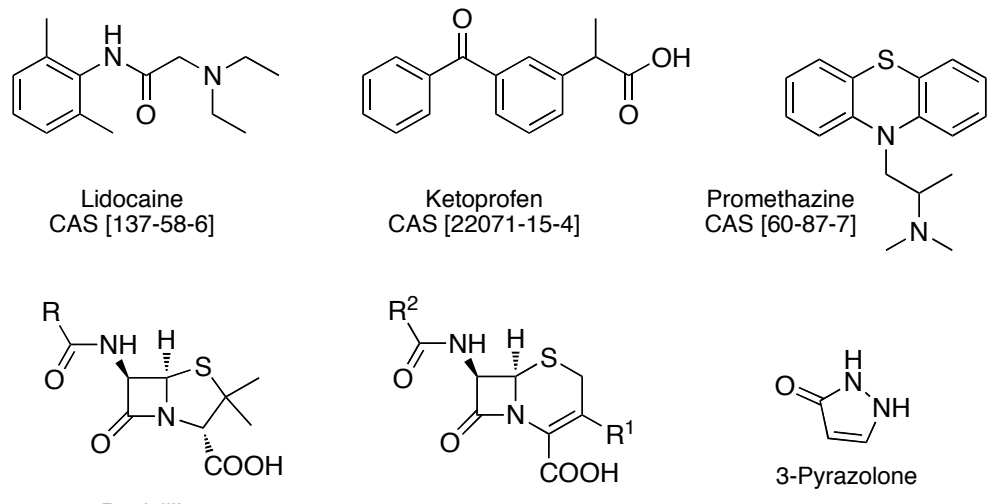

Penicillins

Cephalosporins
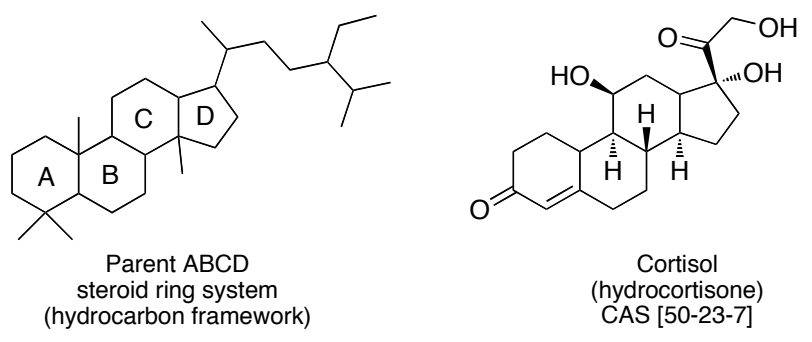
Fig. 5.
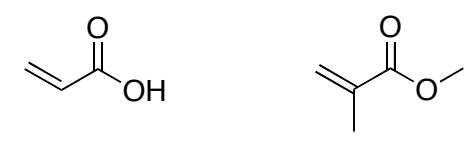

Methyl methacrylate

CAS [80-62-6]

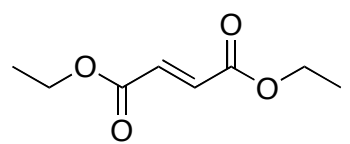

Acrylic acid

Diethyl fumarate

CAS [623-91-6]<smiles>Nc1ccc(N)cc1</smiles>

$p$-Phenylenediamine CAS [106-50-3]

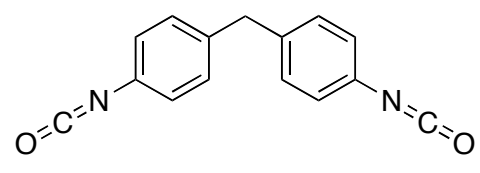

Diphenylmethane-4,4'-diisocyanate CAS [101-68-8]<smiles>CC(C)(c1ccc(OCC(O)COc2ccc(C(C)(C)c3ccc(OCC4CO4)cc3)cc2)cc1)c1ccc(OCC2CO2)cc1</smiles>

Bisphenol A epoxy resin<smiles>CC(C)(c1ccc(O)cc1)c1ccc(O)cc1</smiles>

Bisphenol A

CAS [80-05-7] 